\title{
Michael Hochberg: An Editor's Guide to Writing and Publishing Science
}

\author{
Edward R. Adlard ${ }^{1}$
}

(c) Springer-Verlag GmbH Germany, part of Springer Nature 2019

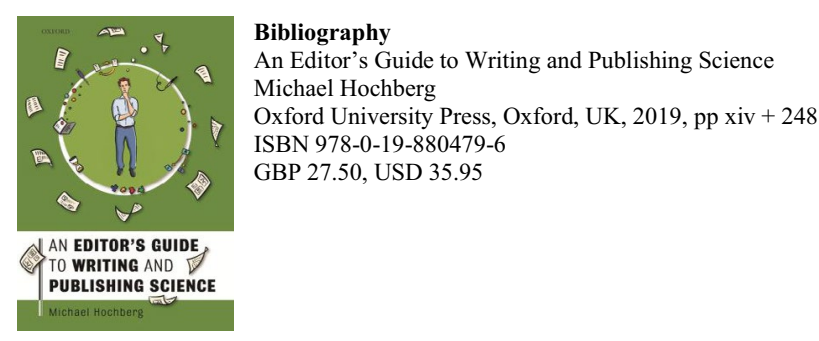

It was pointed out to me by my superiors very early in my career that it was no use being a brilliant scientist (which they assured me I wasn't) if I could not communicate clearly what I was doing and why. One of the first books I ever reviewed for Chromatographia was "The Chemist's English" by the late Robert Schoenfeld which contained the gem which had apparently been submitted to the Australian Journal of Zoology "Rabbits were observed using binoculars"!

Fortunately for the English language it is not burdened by any equivalent of the constrictions imposed by the Académie française so no one becomes "distrait" by the mention of a "coup d'etat" often in a distant former colony. It is clear that there is no shortage of advice on writing scientific communications, and this book gives a list of suggested reading. So what has the book to offer? There are $6 \mathrm{sec}-$ tions further divided into 30 chapters and since there are a total of less than 250 pages it follows that each chapter is small, averaging about 6 pages and ranging from 3 to a maximum of 11. Section 1 "Before you begin" contains four chapters- - Planting your flag" (on other words describing your discovery), "Quality and productivity" (quality is often downgraded for the sake of productivity, I fear), "Citing, reading and searching" and "Avoiding plagiarism". Section 2 of six chapters contains advice on the actual writing of a paper. The five chapters of Section 3 recommend where to publish. Section 4 "Submission and decision" contains four chapters. Section 5 describes peer review and cost of publishing. The last section contains six chapters and gives advice among other things on such topics as collaboration and writing reviews.

It is a sad fact that the majority of young scientists are woefully poor at both writing and verbally presenting their work and their careers can suffer as a consequence. Conversely, I have known a few people, who, while not being particularly good scientists, have good presentation skills and have done extremely well in their organisations as a result. Because many scientists are poor communicators, this book is a "must have" purchase.

At the beginning of each chapter there is a cartoon in colour which is a pictorial summary of the contents. These cartoons are the work of Alex Cagan and although they do not impart any additional information they do lighten the presentation and make a pleasant addition to the book. It should be noted that although the book quite rightly stresses clear and concise presentation, it is not concerned, with the niceties of English grammar, as opposed to the book cited above.

This book is recommended reading for all those involved in presenting their results both verbal and written.

Publisher's Note Springer Nature remains neutral with regard to jurisdictional claims in published maps and institutional affiliations.
Edward R. Adlard

e.adlard77@btinternet.com

1 Burton, UK 